\title{
Strange bedfellows in even stranger places: the role of ATM in meiotic cells, lymphocytes, tumors, and its functional links to p53
}

\author{
R. Scott Hawley ${ }^{1}$ and Stephen H. Friend ${ }^{2}$ \\ ${ }^{1}$ Department of Genetics, Section of Molecular and Cellular Biology, University of California at Davis, Davis, California \\ 95616 USA; $^{2}$ The Seattle Project, Program in Molecular Pharmacology, Fred Hutchinson Cancer Research Center, \\ Seattle, Washington 98104 USA
}

The human disease ataxia telangiectasia (AT) results from an absence of the wild-type product of the ATM gene (Savitsky et al. 1995). At the organismal level, AT is manifested by progressive cerebellar degeneration, the appearance of damaged blood vessels in the skin and in the conjunctiva of the eyes, a predisposition to malignancies (especially lymphomas), gonadal atrophy, and exquisite sensitivity to ionizing radiation. In addition, heterozygotes for mutations in the ATM gene also manifest a much heightened cancer susceptibility, and cells from these patients exhibit an intermediate sensitivity to gamma irradiation (Swift et al. 1991). Although all cases of AT appear to be the result of mutations in the ATM gene, there is some genetic heterogeneity to this disorder that may reflect either phenotypic variation among the mutant alleles or the interaction of ATM mutations with mutations in other functionally related genes (Savitsky et al. 1995; Gilad et al. 1996).

Cells from patients with AT have high levels of spontaneous chromosome breaks and rearrangements, and irradiation greatly increases the number of such breaks (Friedberg et al. 1995). AT cells also appear to be defective in multiple checkpoints for damaged DNA (Meyn 1995). For example, unlike normal cells, AT cells fail to arrest DNA replication when irradiated in $S$ phase. Irradiated AT cells also fail to show a normal delay in the transition from $G_{1}$ to $S$, again suggesting a defect in a DNA damage-sensitive cell-cycle checkpoint (Friedberg et al. 1995). Thus, mutations in the ATM gene appear to void a DNA damage-sensitive checkpoint that prevents cells with damaged chromosomes from entering mitosis (Rudolph and Latt 1989). Indeed, the cellular pathology associated with loss of ATM function suggests a defect in the ability of AT cells to halt their cell cycles in the presence of naturally occurring DNA damage (Murray 1992).

Two recent papers describe a similar set of defects in mice bearing targeted disruptions of the mouse ATM gene (Barlow et al. 1996; Xu et al., this issue). Like their human counterparts, these mice, and tissues derived from them, display extreme radiosensitivity as well as defects in cell-cycle arrest following irradiation. In addition, these mice show poor growth as well as impairment of at least some forms of normal cellular proliferation. These include the development of the germ-lines of both sexes and of $\mathbf{B}$ and $\mathrm{T}$ lymphocytes. These mice are also highly susceptible to thymic lymphoma, and most ATM-deficient mice die by 4 months of age. Finally, one of the two ATM-disruption mouse models presents neurological defects comparable to some problems observed in ATM-deficient humans (Barlow et al. 1996).

The ATM gene encodes a protein similar to several yeast and mammalian PIK-related kinases involved in cell-cycle control (Savitsky et al. 1995). Specifically, the ATM gene is homologous to the MEC1 and TEL1 genes of Saccharomyces cerevisiae, the rad3 gene of Schizosaccharomyces pombe, and the mei-41 gene of Drosophila melanogaster (Jimenez et al. 1992; Kato and Ogawa 1994; Weinert et al. 1994; Greenwell et al. 1995; Hari et al. 1995; Morrow et al. 1995). All of these genes are required for DNA damage-sensitive checkpoint controls and produce repair deficient phenotypes when mutated. In mammals, the ATM protein is also related to a DNAdependent protein kinase (Hartley et al. 1995) and to an ATM-related kinase called both ATR and FRP1 because it is related to FRAP, the FKBP12-rapamycin associated protein (Cimprich et al. 1996; Bentley et al. 1996). The carboxyl terminus of the ATM gene is also homologous to a family of signal transduction proteins, including TOR 1 and TOR2 from S. cerevisiae, involved in controlling the $G_{1} / S$ transition (Helliwell et al. 1994). Thus, both the phenotypes observed in AT cells and the homology of the ATM protein to other genes known to be essential for known damage-sensitive checkpoint genes suggests that ATM plays a major role in coordinating the ability of the cell to monitor its progression through the cell cycle, especially in the presence of DNA damage.

However, it has never been clear that the effects of 
ATM with respect to the response to DNA damage alone are sufficient to explain the pathology of the disease. Similarly, the role of ATM-like proteins as "town crier proteins," whose sole function is to alert the cell to DNA damage, does not explain sufficiently the pleiotropic effects of the homologous mei-41 mutations in Drosophila on meiotic recombination, mitotic cell division, and early embryogenesis (Baker and Carpenter 1972; Baker et al. 1976, 1978; Gatti 1979) or the essential function(s) of MECl in yeast (Kato and Ogawa 1994). Rather, many of us have imagined that ATM and ATM-like proteins, such as MEI-41 and MEC1, must also play crucial roles in normally developing or undamaged cells in order to explain the neurological, immune, and reproductive problems observed in AT patients. This issue of Genes and Development includes three papers that provide strong support for this assertion. Most notably, the paper by $\mathrm{Xu}$ and Baltimore demonstrates not only that ATMdeficient mouse embryonic fibroblasts are defective in their ability to arrest following DNA damage, but that undamaged cells are also defective in the normal progression of the cell cycle, as assayed by their response from $G_{1}$ to $S$ following stimulation with serum. Furthermore, the paper by Xu et al. also demonstrates a direct role for the ATM protein in meiosis and in lymphocyte differentiation, as well as in a number of other biological processes leading to normal growth.

Perhaps more crucially, $\mathrm{Xu}$ and Baltimore (this issue) provide direct evidence that ATM acts as an up-regulator of p53. Specifically, these authors demonstrate that ATM-deficient fibroblasts fail to up-regulate p53 following gamma irradiation. This finding alone is important because it resolves a number of contradictory reports in the literature (Kastan et al. 1992; Khanna and Lavin 1993; Lu and Lane 1993). We will argue below that the interaction between ATM and p53 is of central importance in the ATM story in both damaged and undamaged cells. Perhaps appropriately, the beginning of this story lies in the germ-line.

\section{ATM as a protein involved in meiotic recombination}

Keegan et al. (this issue) demonstrate that the ATM protein is localized along the synapsed regions of meiotic bivalents in both spermatocytes and oocytes. An ATMrelated protein, ATR, can also be found in a complementary pattern, namely along the remaining unsynapsed regions of the bivalent. The importance of this localization in the meiotic process is evidenced by the finding of $\mathrm{Xu}$ et al. (this issue) that meiosis in ATM-deficient mice is arrested at zygotene/pachytene of meiosis and that the arrested cells show high levels of both asynapsis and chromosome fragmentation. Moreover, patients with AT frequently exhibit gonadal abnormalities associated with reduced numbers of germ cells.

The punctate pattern of ATM localization on pachytene bivalents is reminiscent of the location of proteins such as the RecA homolog Rad51 that are believed to be components of the recombination nodule (RN)
(Bishop 1994; Ashley et al. 1995; Terasawa et al. 1995; Plug et al. 1996). Recombination nodules, discovered by Adelaide Carpenter in the early 1970s, are densely staining structures present on the synaptonemal complex, the ribbon-like structure that connects paired homologs in meiotic cells (Carpenter 1988). Although there are two types of RNs (early and late) in most organisms, we will be concerned here only with the role of late RNs. Late RNs are known to mark the sites of meiotic exchange, but their function with respect to exchange initiation, maturation, and chiasma function remains unclear.

The suggestion that the ATM protein might be an essential component of the recombination nodule is strengthened by the observation that mei- 41 mutations have dramatic effects both on the frequency of meiotic recombination, lowering it approximately twofold, and on the morphology of the late nodules (Carpenter 1979). mei-41 nodules differ from normal nodules in two important ways. First, the RNs in mei-41 oocytes are uniformly less dense than are normal RNs, and, second, unlike normal RNs, the RNs in mei-41 oocytes are associated with regions of diffuse or uncondensed chromatin.

Given the structural and functional homologies between the MEI-41 and ATM proteins, the meiotic phenotype of mei-41 with respect to RNs, and the punctate localization of ATM along meiotic bivalents in mammalian pachytene cells, it does not seem unreasonable to suggest that ATM is likely to be a component of the RN. We propose that ATM plays several important roles in the meiotic process, consistent with a possible location within the RN. These include, but are not limited to, the assessment of the integrity of the recombination intermediate and the control of chromosome condensation in the immediate vicinity of the recombination intermediate.

The suggestion that ATM may play a role in assaying the integrity of the recombination intermediate is based on studies of a yeast ATM homolog known as MECl. Recently, Lydall et al. (1996) have shown that MEC1 is required in order for abnormal or incomplete meiotic events to trigger a pachytene arrest. The pachytene arrest observed in mutants such as DMC1, which block formation of the recombination intermediate, is bypassed in the absence of functional MECl gene product. Moreover, in the absence of other mutations, mec1 mutant cells enter the first meiotic division before all recombination events are complete. These data suggest that in yeast the MEC1 protein plays a crucial role in ensuring that recombination events are complete before proceeding into the meiotic divisions.

We imagine that in the absence of ATM protein, improperly matured meiotic recombination events may produce chromosome breaks of the type observed by Keegan et al. (this issue). Similarly, the induction of sister chromatid exchanges within the ribosomal RNA gene cluster in the germ-lines of mei-41 Drosophila males results in a high frequency of newly arising translocations with one breakpoint in the rDNA cluster (Hawley and Tartof 1983). Hawley and Marcus (1989) have interpreted these results to mean that, in the pres- 
ence of the mei-41 mutation, improperly processed recombination intermediates become double-stranded breaks (DSBs) that are repaired as translocation events. Incomplete processing of recombination events in cells deficient for ATM-like proteins may also explain the high frequency of translocation with one break in the region of the T-cell receptor gene complex observed in lymphomas of AT patients (Kogis et al. 1991).

ATM-like proteins may also play a critical role in mediating chromosome condensation in the vicinity of the recombination intermediate, as suggested by the diffuse chromatin seen in mei-41 oocytes. Recently, Kleckner (1996) has argued that chromosome condensation in the area of the exchange event may be an important regulator of overall compaction along the chromosome arm, and thus not only may play a role in coordinating various events within the meiotic process, but perhaps also may serve a function in controlling the relative position of exchange events. Indeed, mei- 41 bearing oocytes exhibit a strong relaxation in the effectiveness of chiasma interference, the process that serves to keep exchanges on the same chromosome arm positioned far apart.

\section{Exploring links between ATM and p53}

However, neither coordinating chromosome compaction nor determining the relative position of exchange events would seem sufficient to explain the rather global effects on the meiotic process seen in ATM-deficient mice. Xu et al. (this issue) observed significant amounts of bivalent fragmentation and asynapsis. Nor can a function devoted to the recognition of presumably rare errors easily explain the exchange reduction seen in mei-41 oocytes. We propose that the correct answer to this dilemma may in fact be the most obvious one, that ATM or ATM-like proteins are intimately associated with both $\mathrm{p} 53$ and with the molecular machinery required for the execution of exchange events themselves. The evidence for such a seemingly heretical hypothesis can be gathered from several observations.

First, it is worth noting that the expression pattern of p53 parallels that of ATM. Both proteins are highly expressed in the primary spermatocytes at the pachytene stage during meiosis I (Rotter et al. 1994). Looking more closely at the interacting proteins, there is a recent report that, a least in vitro, p53 interacts physically with the human RAD51 protein and may play a direct role in mediating meiotic recombination (Stürzbecher et al. 1996). Moreover, mice with reduced levels of p53 exhibit a testicular degenerative syndrome, similar to that seen for the ATM-deficient mice, which is consistent with a defect in completion of meiotic prophase (Rotter et al. 1993)

Based on these data, we suggest that ATM and p53 are both components of the $\mathrm{RN}$ and thus present at the site of the exchange. As members of this protein complex, they could monitor the status of the initiating DSB, its maturation into a recombination intermediate, and its resolution into mature crossover products. We further speculate that this complex containing p53 and ATM acts at several times during the meiotic process. One can imagine that the signals created by a putative ATM-p53 complex might include: signaling a normal pause in cellcycle progression to allow the completion of recombination, reporting a failed or abnormal resolution event leading to an apoptotic meiotic arrest, or allowing the next step in the exchange resolution process. As detailed in the next section, we also propose that this rather tight association between ATM, RAD51, p53, and the control of recombination may not be limited to the germ-line.

\section{The role of ATM in the development of the immune system}

Most patients with AT exhibit humoral and cellular and immune defects. Similarly, the ATM-deficient mice created by Xu et al. (this issue) and by Barlow et al. (1996) also exhibit severe defects in immune system development manifested by reduced number of pre-B cells, thymocytes, and peripheral T cells. Xu et al. (this issue) also have demonstrated a functional impairment of $\mathrm{T}$ cellindependent immune responses.

Although patients and mice with germ-line p53 heterozygous mutations have not been noted to have immune deficiencies, p53 plays a key role in lymphoid development. Some of the first clues came from studies of early pre-B cell lines: Whereas overexpression of p53 in most cell lines results in induction of apoptosis, the overexpression of p53 in these early pre-B cell lines facilitated their differentiation into more mature pre-B cells with a prolonged doubling time (Shaulsky et al. 1991). In other experiments, where a differentiation agent LPS results in recombination and rearrangement of the kappa light chain, it was shown that this differentiation was preceded by an up-regulation of the p 53 gene. Aloni-Grinstein et al. (1993) found that mutant p53 blocked this differentiation process. p53 also appears to signal a recombination-triggered arrest necessary for B-cell differentiation. This parallels the reduction of mature $\mathrm{B}$ cells seen in the ATM-deficient mice (Xu et al., this issue). There is little data on p53-deficient $T$ cells to use for comparison with the clear role ATM has in the process of $\mathrm{V}(\mathrm{D})]$ recombination in $\mathrm{T}$ cells.

\section{ATM as a cancer susceptibility gene}

The close physical and functional connections between the ATM gene product and p53 protein just mentioned are quite apparent when one turns to a comparison of the similar nature by which these two genes can provide a high susceptibility to cancer. Unfortunately, many of the patients with AT die by the second or third decade of life as a result of neurologic deterioration or the development of tumors. Among the patients carrying homozygous inactivations of the ATM gene, $\sim 10-15 \%$ of these patients acquire lympho-reticular malignancies. Heterozygous carriers have been reported to have a higher incidence of breast cancer (Swift et al. 1991). The two recent descriptions of ATM-deficient mice show a high 
incidence of lymphomas, particularly thymic lymphomas. Similar to their human counterparts, the ATM-disruption mice also quite often develop these thymic lymphomas. Immunologic analysis of these tumors show that they are invariably $\mathrm{CD} 4+, \mathrm{CD} 8+$, and thus apparently represent immature thymocytes. However, the heterozygous ATM mice have revealed no increased incidence of breast tumors.

Similarly, patients heterozygous for p53 mutations in their germ-lines exhibit Li-Fraumeni syndrome. This syndrome has an associated high frequency of sarcomas, breast cancers, leukemias, lymphomas, brain tumors, and adrenal cortical tumors $\langle\mathrm{Li}$ and Fraumeni 1969; Srivastava et al. 1990, 1992). The heterozygous p53 mice have a high incidence of osteosarcomas, brain tumors, and lung adenocarcinomas. The homozygous p53-disruption mice develop an extraordinary frequency of lymphomas, followed by carcinomas and other tumors. It is striking that the ATM-deficient and p53-deficient mice are so remarkably sensitive to lymphomas. Similar to the ATM-deficient mice, in the p53-deficient mice lymphomas are primarily thymic lymphomas and are again both CD4 and CD8 positive.

The significant overlap in distribution of tumors found in the human and mouse models for p53 and AT suggests that defects in the ATM gene result in a subset of the tumors seen in the animals who lack p53. The fact that the ATM-deficient cells are unable to trigger the p53 response suggests a model by which, in those situations where the ATM gene is needed as a sensor to trigger p53, the absence of ATM will result in a cancer susceptibility phenotype that resembles p53 disruption. Following others (Hartwell 1992; Murray 1992), we imagine that the tumors observed in ATM and p53-deficient patients are the result of the genomic instability induced by these mutations. To the extent that the role of p53 and its association with the recombination machinery is present in order to couple defects in recombination resolution with a halt of the cell cycle, the tumors that arise in the ATM-deficient cells most likely arise because of the increased genetic instability that occurs when recombination is uncoupled from a proper arrest of cellcycle progression. This would generate the type of genetic instability that previously has been associated with loss of the p53 gene. Such a model, although possible, should be held lightly until additional data is accumulated. This warning is particularly apt, considering the fact that mice made both rag1- and p53-deficient still develop thymic lymphomas (Mombaraerts et al. 1995).

\section{Conclusions}

The work described above clearly illustrates the value of the ATM-disruption mouse model as a critical tool for the study of the human disease. Most critically, the mouse system provides a clear view of the function of ATM and ATM-like proteins in undamaged cells, such as meiotic cells and lymphocytes. In most cases, that role appears to still be centered on the processing of DNA breaks arising in various normal contexts. The mouse system will also provide the best possible tool for assaying the role of ATM in the development of the nervous system, as a basis for understanding the neuropathology of AT.

The papers also suggest that the ATM-like proteins may exert their effects through coupling of meiotic and mitotic recombination events with the cell-cycle engine, control of chromosome compaction in meiotic cells, and direct effects of the replication and recombination processes. We further suggest that at least by the criteria of "motive and opportunity" it seems reasonable to suggest that many of these processes may include a direct functional interaction with p53 or a functional homolog of p53. We would not, however, be in the least surprised if the exact nature of that interaction varied both within and between cell types. What now remains to be explored is the degree to which these apparent functional interactions reflect physical associations or protein modifications at the biochemical level. For example, do p53 and ATM actually both associate with each other or with RAD51? If so, how do they talk to each other? The answer to these questions will represent one of the next crucial steps in our understanding of AT.

\section{Acknowledgments}

We thank Drs. Adelaide Carpenter, Katherine DeYoung, Leland Hartwell, Tyler Jacks, Kara Koehler, Anne Laurencon, Kim McKim, Varda Rotter, Jeff Sekelsky, and David Weaver for valuable discussions. R.S.H. and S.F. both gratefully acknowledge the support of Mr. Brad Margus and the A-T Children's Project.

\section{References}

Aloni-Grinstein, R., R. Zan-Bar, I. Alboum, N. Goldfinger, and V. Rotter. 1993. Wild-type p53 functions as a control protein in the differentiation pathway of the B-cell lineage. Oncogene 8: 3297-3305.

Ashley, T., A.W. Plug, J. Xu, A.J. Solari, G. Reggy, E.I. Golub, and D.C. Ward. 1995. Dynamic changes in Rad51 distribution on chromatin in meiosis in male and female vertebrates. Chromasoma 104: 19-28.

Baker, B.S. and A.T.C Carpenter. 1972. Genetic analysis of sex chromosomal meiotic mutants in Drosophila melanogaster. Genetics 90: 255-286.

Baker, B.S., J.B. Boyd, A.T.C. Carpenter, M.M. Green, T.D. Nguyen, P. Ripoll, and P.D. Smith. 1976. Genetic controls of meiotic recombination and somatic DNA metabolism in Drosophila melanogaster. Proc. Natl. Acad. Sci. 73: 41404144.

Baker, B.S., A.T.C. Carpenter, and P. Ripoll. 1978. The utilization during mitotic cell division of loci controlling meiotic recombination in Drosophila melanogaster. Genetics 90: $531-578$.

Barlow, C., S. Hirotsune, R. Paylor, M. Liyanage, M. Eckhaus, F. Collins, Y. Shiloh, I.N. Crawley, T. Ried, D. Tagle, and A. Wynshaw-Boris. 1996. Atm-deficient mice: A paradigm of Ataxia telangiectasia. Cell 86: 159-171.

Bentley, N.J., D.A. Holtzman, G. Flaggs, K.S. Keegan, A. DeMaggio, J.C. Ford, M. Hoekstra, and A.M. Carr. 1996. The S. pompe rad3 checkpoint gene. EMBO $J$.

Bishop, D.K. 1994. RecA homologues Dmcl and Rad51 interact to form discrete nuclear complexes prior to meiotic chromo- 
some synapsis. Cell 79: 1081-1092.

Carpenter, A.T.C. 1979. Recombination nodules and synaptonemal complex in recombination-defective females of Drosophila melanogaster. Chromosoma 75: 259-292.

- 1988. Thoughts on recombination nodules, meiotic recombination and chiasmata. In Genetic recombination (ed. R. Kucherlapati and G. Smith|, pp. 526-548. American Society for Microbiology, Washington, DC.

Cimprich, K.A., T.B. Shin, C.T. Keppi, and S.L. Schreiber. 1996. cDNA cloning and gene mapping of a candidate human cell cycle checkpoint protein. Proc. Natl. Acad. Sci. 93: 28502855.

Friedberg, E.C., G.C. Walker, and W. Siede. 1995. DNA repair and mutagenesis. ASM Press, Washington, DC.

Gatti, M. 1979. Genetic control of chromosome breakage and rejoining in Drosophila melanogaster: Spontaneous chromosome aberrations in X-linked mutants defective in DNA metabolism. Proc. Natl. Acad. Sci. 76: 1377-1381.

Gilad, S., R. Khosravi, D. Shkedy, T. Uziel, T. Ziv, and K. Savitsky et al. 1996. Predominance of null mutations in Ataxia telangiectasia. Hum. Mol. Genet. 5: 433-439.

Greenwell, P.W., S.L. Kronmal, S.E. Porter, J. Gasenhuber, B. Obermaier, and T.D. Petes. 1995. TELl, a gene involved in controlling telomere length in $S$. cerevisiae, is homologous to the human ataxia telangiectasia gene. Cell 82: 823-829.

Hari, K.L., A. Santerre, J.J. Sekelsky, K.S. McKim, K.S., J.B. Boyd, and R.S. Hawley. 1995. The mei-41 gene of D. melanogaster is a structural and functional homolog of the human ataxia telangiectasia gene. Cell 82: 815-821.

Hartley, K.O., D. Gell, G.C. Smith, H. Zhang, N. Divecha, M.A. Connelly, A. Admon, S.P. Lees-Miller, C.W. Anderson, and S.P. Jackson. 1995. DNA-dependent protein kinases catalytic subunit: A relative of phosphatidlyinositol 3- kinase and the ataxia telangiectasia gene product. Cell 82: 849-856.

Hartwell, L.H. 1992. Defects in a cell cycle checkpoint may be responsible for the genome instability of cancer cells. Cell 71: 543-546.

Hawley, R.S. and C.H. Marcus. 1989. Recombinational controls of rDNA redundancy in Drosophila. Annu. Rev. Genet. 23: $87-120$.

Hawley, R.S. and K.D. Tartof. 1983. The effect of mei-41 on rDNA redundancy in Drosophila melanogaster. Genetics 104: $63-80$

Helliwell, S.B., P. Wagner, J. Kunz, M. Deuter-Reinhard, R. Henriquez, and M.N. Hall. 1994. TOR1 and TOR2 are structurally and functionally similar but not identical phosphatidylinositol kinase homologues in yeast. Mol. Biol. Cell 5: 105118.

Jimenez, G., J. Yucel, R. Rowley, and S. Subramani. 1992. The $\mathrm{rad}^{+}$gene of Schizosaccharomyces pombe is involved in multiple checkpoint functions and in DNA repair. Proc. Natl. Acad. Sci. 89: 4952-4956.

Kastan, M.B., Q. Zhan, W.S. El-Deiry, F. Carrier, T. Jacks, W.V. Walsh, B.S. Plunkett, B. Vogelstein, and A.J. Fornace, Jr. 1992. A mammalian cell cycle checkpoint pathway utilizing p53 and GADD45 is defective in Ataxia Telangiectasia. Cell 71: $587-597$.

Kato, R. and H. Ogawa. 1994. An essential gene, ESRl, is required for mitotic cell growth, DNA repair and meiotic recombination in Saccharomyces cerevisiae. Nucleic Acids Res. 22: 3104-3112.

Keegan, K.S., D.A. Holtzman, A.W. Plug, E.R. Christenson, E.E. Brainerd, G. Flaggs, N.J. Bentley, E.M. Taylor, M.S. Meyn, S.B. Moss, A.M. Carr, T. Ashley, and M.F. Hoekstra. 1996. The Atr and Atm protein kinases associated with different sites along meiotically pairing chromosomes. Genes \& Dev. (this issue).

Khanna, K.K. and M.F. Lavin. 1993. Ionizing radiation and UV induction of p53 protein by different pathways in ataxiatelangiectasia cells. Oncogene 8: 3307-3312.

Kleckner, N. 1996. Meiosis: How could it work? Proc. Natl. Acad. Sci. 93: 8167-8174.

Kogis, T.L., R.A. Gatti, and R.S. Sparkes. 1991. The cytogenetics of Ataxia telangiectasia. Cancer Genet. Cytogenet. 56: 143 156.

Li, F. and J. Fraumeni. 1969. Soft-tissue sarcomas, breast cancer, and other neoplasms: A familial syndrome? Ann. Intern. Med. 71: 747-753.

Lu, X. and D.P. Lane. 1993. Differential induction of transcriptionally active p53 following UV or ionizing radiation defects in chromosome instability syndromes? Cell 75: 765778.

Lydall, D., Y. Nikolsky, D.K. Bishop, and T. Weinert. 1996. A meiotic recombination checkpoint controlled by mitotic checkpoint genes. Nature (in press).

Meyn, S. 1995. Ataxia telangiectasia and cellular responses to DNA damage. Cancer Res. 55: 5991-6001.

Mombaraerts, P., C. Terhorst, T. Jacks, S. Tonegawa, and J. Sancho. 1995. Characterization of immature thymocyte lines derived from $\mathrm{T}$-cell receptor or recombination activating gene 1 and p53 double mutant mice. Proc. Natl. Acad. Sci. 92: 7420-7424.

Morrow, D.M., D.A. Tagle, Y. Shiloh, F.S. Collins, and P. Hieter. 1995. TELl, an $S$. cerevisiae homolog of the human gene mutated in ataxia telangiectasia, is functionally related to the yeast checkpoint gene MEC1. Cell 82: 831-840.

Murray, A. 1992. Creative blocks: Cell cycle checkpoints and feedback controls. Nature 359: 599-604.

Plug, A.W., J. Xu, G. Reddy, E.I. Golub, and T. Ashley. 1996. Presynaptic association of Rad51 protein with selected sites in meiotic chromatin. Proc. Natl. Acad. Sci. 93: 5920-5924.

Rotter, V., R. Aloni-Grinstein, D. Schwartz, N. B. Elkind, A. Simons, R. Wolkowicz, M. Lavigne, P. Beserman, A. Kapon, and N. Goldfinger. 1994. Does wild-type p53 play a role in normal cell differentiation? Semin. Cancer Biol. 5: 229-236.

Rudolph, N.S. and S.A. Latt. 1989. Flow cytophotometric analysis of X-ray sensitivity in ataxia telangiectasia. Mutat. Res. 211: $31-41$.

Savitsky, K., A. Bar-Shira, S. Gilad, G. Rotman, Y. Ziv, L. Vanagaite, D.A. Tagle, S. Smith, T. Uziel, S. Sfez, et al. 1995. A single ataxia-telangiectasia gene with a product similar to PI-3 kinase. Science 268: 1749-1753.

Shaulsky S., N. Goldfinger, A. Peled, and V. Rotter. 1991. Involvement of wild p53 in pre-B cell differentiation in vivo. Proc. Natl. Acad. Sci. 88: 8982-8986.

Srivastava, S., Z. Zou, K. Pirollo, W. Blattner, and E.H. Chang. 1990. Germ-line transmission of a mutated p53 gene in a cancer prone family with Li-Fraumeni syndrome. Nature 348: 747-749.

Srivastava, S., Y. Tong, K. Devadas, Z.-Q. Zou, V. Sykes, Y. Chen, W. Blattner, K. Pirollo, and E. Chang. 1992. Detection of both mutant and wildtype p53 proteins in normal skin fibroblasts and demonstration of a "second-hit" on p53 in diverse tumors from a cancer-prone family with Li-Fraumeni Syndrome. Oncogene 7: 987-991.

Stürzbecher, H., B. Donzelmann, W. Henning, U. Knippschild, and S. Buchhop. 1996. p53 is linked directly to homologous recombination processes via RAD51/RecA protein interaction. EMBO J. 15: 1992-2002.

Swift, M., D. Morrell, R.B. Massey, and C.L. Chase. 1991. Incidence of cancer in 161 families affected by ataxia telangiectasia. N. Engl. J. Med. 325: 1831-1836. 
Terasawa, M., A. Shinohara, Y. Hotta, H. Ogawa, and T. Ogawa. 1995. Localization of RecA-like recombination proteins on chromosomes of lily at various meiotic stages. Genes \& Dev. 9: 925-934.

Weinert, T. and D. Lydall. 1993. Cell cycle checkpoints, genetic instability and cancer. Semin. Cancer Biol. 4: 129-140.

Weinert, T.A., G. Kiser, and L.H. Hartwell. 1994. Mitotic checkpoint genes in budding yeast and the dependence of mitosis on DNA replication and repair. Genes \& Dev. 8: 652-665.

$\mathrm{Xu}$, Y. and D. Baltimore. 1996. Dual roles of ATM in the cellular response to radiation and in cell growth control. Genes \& Dev. (this issue).

Xu, Y., T. Ashley, E.E. Brainerd, R.T. Bronson, M.S. Meyn, and D. Baltimore. 1996. Targeted disruption of ATM leads to growth retardation, chromosomal fragmentation during meiosis, immune defects, and thymic lymphoma. Genes \& Dev. (this issue). 


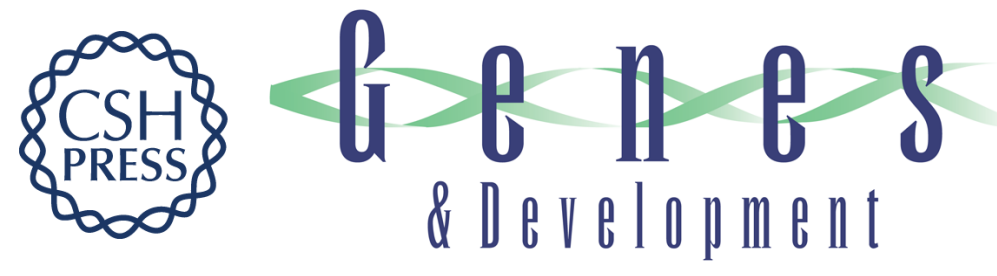

\section{Strange bedfellows in even stranger places: the role of ATM in meiotic cells, lymphocytes, tumors, and its functional links to p53.}

R S Hawley and S H Friend

Genes Dev. 1996, 10:

Access the most recent version at doi:10.1101/gad.10.19.2383

References This article cites 42 articles, 15 of which can be accessed free at:

http://genesdev.cshlp.org/content/10/19/2383.full.html\#ref-list-1

License

Email Alerting

Service

Receive free email alerts when new articles cite this article - sign up in the box at the top right corner of the article or click here.

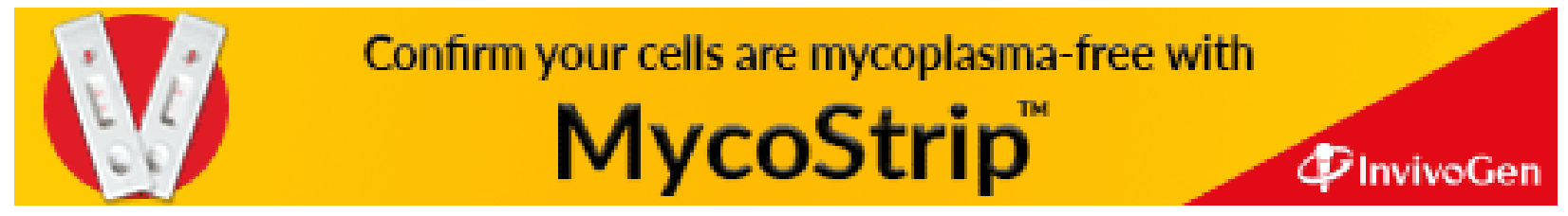

